\title{
Perfil epidemiológico dos acidentes automobilísticos na cidade de Volta Redonda-RJ, no ano de 2015
}

\author{
Epidemiological profile of automobile accidents in the city of Volta \\ Redonda-RJ, in 2015
}

\author{
1 Glauber Correia de Oliveira glauber.medicina@hotmail.com \\ 2 Priscila da Silva Marcelino
}

1 Médico formado pela Escola de Ciências Médicas de Volta Redonda (UniFOA) e residente de Cirurgia Geral pela Faculdade de Medicina de Marília (FAMEMA).

2 Enfermeira formada pelo Centro Universitário de Volta Redonda (UniFOA) e pós-graduanda em Auditoria e Gestão em Serviços de Saúde pelo Instituto de Ensino, Capacitação e Pós-graduação (Indep).

\section{Resumo}

As causas externas (em especial, os acidentes de trânsito) estão entre as principais causas de morbimortalidade no mundo, atingindo principalmente a população economicamente ativa e em idade fértil, causando sério impacto na sociedade. Nosso objetivo foi traçar um perfil epidemiológico dos acidentes de trânsito ocorridos na Cidade de Volta Redonda-RJ, em 2015, e possibilitar discussões com gestores, a fim de reduzir esses acidentes. Para isso, realizamos um estudo transversal, coletando dados do DATASUS (abertos ao público). Os descritores primários foram "acidentes de transporte", "cidade de Volta Redonda" e "ano de 2015"; os descritores secundários buscaram outras informações relevantes (como "faixa etária", "gastos", "gênero", "óbitos", "tipos de acidente de transporte", entre outros). Após análise dos dados, observamos um total de 276 internações, a maioria de motociclistas $(51,45 \%)$, de pedestres $(21,01 \%)$ e de ocupantes de veículos de passeio (16,67\%). Foram gastos $\mathrm{R} \$$ $420.581,80$, destinados principalmente a motociclistas $(46,9 \%)$, pedestres $(22,1 \%)$ e ocupantes de veículos de passeio (18,4\%). Houve 15 óbitos, sendo $33,3 \%$ de motociclistas, $33,3 \%$ de pedestres, $26,7 \%$ de ocupantes de veículos de passeio e um (6,7\%) classificado como "outros tipos de acidente de transporte". A maioria das internações e dos óbitos ocorreu na população do sexo masculino. Assim, observou-se grande impacto dos acidentes de trânsito na cidade de Volta Redonda-RJ, seguindo a tendência mundial atual.

\section{Palavras-chave}

Acidentes automobilísticos; morbimortalidade; internações; gastos; prevenção.

\begin{abstract}
External causes (especially traffic accidents) are among the leading causes of morbidity and mortality in the world, affecting mainly the population who are economically active and of childbearing age, causing serious impact on society. Our aim was to outline an epidemiological profile of traffic accidents in Volta Redonda-RJ in 2015, and enable discussions with managers in order to reduce these accidents. Aiming this objective, we conducted a cross-sectional study, collecting data from DATASUS (open to the public). The primary descriptors were "traffic accidents", "Volta Redonda" and "2015"; the secondary descriptors sought other relevant information (such as "age", "incoming", "gender", "death", "types of transport accident," among others). After analyzing the data, we found a total of 276 admissions, mostly motorcyclists (51.45\%), followed by pedestrians (21.01\%) and passenger car occupants (16.67\%). It was spent $R S 420,581.80$, especially for motorcyclists (46.9\%), pedestrians (22.1\%) and passenger car occupants (18.4\%). There were 15 deaths, $33.3 \%$ of motorcyclists; $33.3 \%$ of pedestrians; $26.7 \%$ of passenger car occupants, and $6.7 \%$ were classified as "other types of transport accident." Most hospitalizations and deaths occurred in the male population. So the results show that there was great impact of traffic accidents in the city of Volta Redonda$R J$, which follows the worldwide trend.
\end{abstract}

\section{Keywords}

Traffic accidents, mobility and mortality, hospitalizations, spending, prevention.

\section{Como você deve citar?}

OLIVEIRA, Glauber Correia de; MARCELINO, Priscila da Silva . Perfil epidemiológico dos acidentes automobilísticos na cidade de Volta Redonda-RJ, no ano de 2015 Cadernos UniFOA, Volta Redonda, n. 33, p. 111-119, abr. 2017. 


\section{INTRODUÇÃO}

As causas externas estão, hoje, entre as três principais causas de morbimortalidade no mundo todo (juntamente com doenças cardiovasculares e neoplasias). Na população economicamente ativa, esse grupo de doenças torna-se a principal causa. Isso provoca um grande impacto econômico e social, tanto devido à quantidade de óbitos provocados, quanto à quantidade de indivíduos que desenvolvem alguma sequela (e deixam de exercer suas funções temporária ou definitivamente). Essas sequelas podem ser físicas, emocionais/psíquicas e morais.

Os acidentes de trânsito ocupam certamente parcela importante desse grupo de doenças, se não a parcela mais significativa. As causas para a grande quantidade de acidentes automobilísticos são muitas: aumento da quantidade de veículos nas cidades, consumo de bebidas alcoólicas e/ou substâncias entorpecentes associadas à direção de um veículo, imprudência/imperícia/negligência no trânsito (incluindo alta velocidade, manobras perigosas, falta do uso de equipamentos de segurança, direção de veículos por pessoas não habilitadas, etc.), uso de veículos sem condições mínimas de uso, vias de circulação de veículos sem condições adequadas para o tráfego, entre tantas outras condições observadas no dia a dia.

Segundo estudo realizado na cidade do Rio de Janeiro, $70 \%$ dos casos fatais dos acidentes de trânsito estão relacionados com uso e abuso de bebidas alcoólicas (ABREU et al, 2009). Esse mesmo estudo aponta ainda uma deficiência na fiscalização, quanto ao uso de bebidas alcoólicas pelos condutores de veículos, e ainda menciona que os hospitais de urgência e emergência, referências para receber os pacientes vítimas de trauma no Brasil não realizam o exame de alcoolemia (subestimando a quantidade real de vítimas de acidentes automobilísticos associados ao uso dessas substâncias). Alguns fatores relacionados com acidentes automobilísticos associados ao uso do álcool são: ser homem, solteiro (a), beber em festas e conduzir veículo após o evento, ser passageiro de motorista alcoolizado, baixa incidência de punição ao condutor alcoolizado, baixo nível socioeconômico e baixa escolaridade (SALDANHA et al., 2014).

Outra grande parcela dos acidentes automobilísticos envolve motociclistas. Esse fato se justifica pelo aumento da circulação desses veículos, causado, entre outros motivos, pelo o baixo custo do veículo, facilidade de deslocamento, aumento do uso das motocicletas como instrumento de trabalho e maior facilidade de estacionamento. Além disso, a pequena extensão da lataria das motocicletas, assim como os mecanismos de proteção restritos para os ocupantes do veículo (de forma o que o impacto das colisões/quedas seja absorvido quase que exclusivamente pelo corpo da vítima) e a sua maior dificuldade de visualização fazem com que os acidentes envolvendo motocicletas sejam, no geral, mais graves e mais propensos a provocar vítimas fatais. Em um estudo realizado no Estado do Paraná, entre 2010 e 2011 , apontou que $54,2 \%$ dos acidentes avaliados na pesquisa envolviam motocicletas (GOLIAS e CAETANO, 2013). Outro estudo realizado na cidade de Londrina afirma que a mortalidade entre motociclistas brasileiros aumentou mais de 700\%, de 1998 a 2008 (SANT'ANNA et al., 2013), reforçando a importância desse veículo nas estatísticas de acidentes automobilísticos e suas consequências.

O trabalho de SALDANHA et al (2014) analisou também as diferenças entre homens e mulheres na epidemiologia dos acidentes de trânsito. Segundo os levantamentos literários desse estudo, a maior parcela dos acidentes de trânsitos envolve a população do gênero masculino e, geralmente, envolvida como condutor, enquanto as mulheres, geralmente, são passageiras ou pedestres. Além disso, várias pesquisas apontam que as mulheres estão envolvidas em menos acidentes graves do que os homens, quando a comparação é proporcional. Por exemplo, segundo dados do Detran-DF, no ano de 2011, apenas 1,31/10.000 mulheres estiveram envolvidas em acidentes fatais, enquanto os homens foram 5,94/10.000. Possivelmente essa diferença se dê, não apenas pelo maior número de homens condutores e pelo maior tempo que eles passam no trânsito, mas também porque talvez as mulheres sejam mais cautelosas ao conduzir o veículo. 
Outro estudo realizado na cidade de São Paulo, em 2014, observou que os acidentes de trânsito também ocorrem com frequência na infância e na adolescência, sendo $64,4 \%$ no sexo masculino e $35,6 \%$ no sexo feminino. Desses acidentes, $42,8 \%$ eram causados por automóveis; $40,1 \%$ por motocicletas; $13,6 \%$ por bicicletas; $2,7 \%$ ônibus e 1,4\% ignorados (GORIOS et al, 2014). Devido à não permissão para condução de veículos nessa faixa etária, os acidentes ocorrem geralmente com pedestres (atropelamentos) ou ocupantes de veículos.

Diante do exposto, torna-se clara a importância dos acidentes de trânsito na saúde pública e no bem-estar social. A análise de dados epidemiológicos é necessária para possibilitar avaliações e discussões que visem controlar e até mesmo reduzir a quantidade e a gravidade dessa moléstia da sociedade atual, assim como otimizar o atendimento e a recuperação dessas vítimas.

\section{OBJETIVOS}

O objetivo deste estudo é avaliar o perfil epidemiológico dos acidentes de trânsito ocorridos na cidade de Volta Redonda-RJ, no ano de 2015, para possibilitar uma futura discussão de estratégias de prevenção, de atendimento pré e intra-hospitalar e de reabilitação da população vítima de algum acidente automobilístico, com gestores de saúde e autoridades de trânsito.

\section{METODOLOGIA}

Trata-se de um estudo descritivo/epidemiológico transversal que utilizou o banco de dados do Ministério da Saúde (DATASUS/TABNET) para coleta dos dados relacionados aos acidentes automobilísticos, utilizando como descritores primários "acidentes de transporte", "cidade de Volta Redonda" e "ano de 2015"; e como descritores secundários as demais informações pertinentes (como "internações", "faixa etária", "gastos", "gênero", "óbitos", "tipo de veículo envolvido", "tipo de acidente", etc.)

A partir dos dados coletados foram gerados gráficos em planilhas, utilizando-se o software "Microsoft Excel", a fim de facilitar a interpretação dos dados.

\section{RESULTADOS}

\subsection{Internações}

No período pesquisado foram registradas 276 (duzentas e setenta e seis) internações de vítimas de acidentes de transporte. Desse grupo, $80,41 \%$ (222 pessoas) eram do sexo masculino e 19,6\% (54 pessoas) eram do sexo feminino.

Quanto à idade das vítimas, 12,3\% (34 pessoas) tinham idade entre 0 e 19 anos, (a grande maioria na faixa entre 15 e 19 anos); $50 \%$ (138 pessoas) tinham entre 20 e 39 anos (adultos jovens); $31,1 \%$ (86 pessoas) entre 40 e 59 anos (adultos); e 6,5\% (18 pessoas) estavam na faixa acima de 60 anos. 
Gráfico 1 - Internações por faixa etária

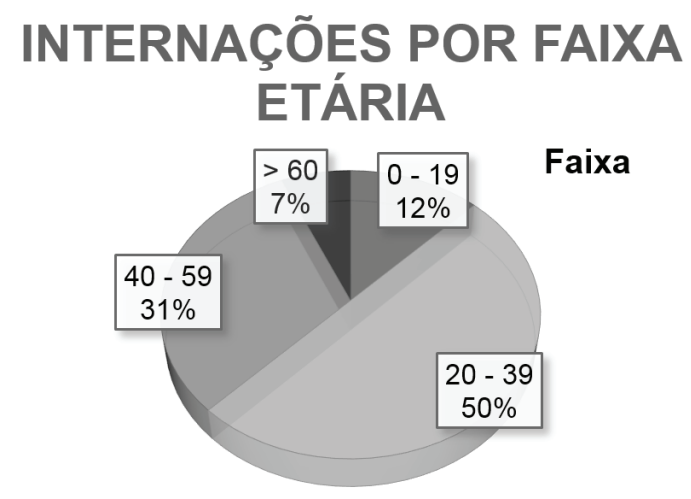

Fonte: dos autores

Ainda em relação às internações, 142 internações $(51,45 \%)$ foram de acidentes envolvendo motociclistas, 58 internações $(21,01 \%)$ de pedestres, 46 internações $(16,67 \%)$ de ocupantes de veículos de passeio, 14 internações $(5,07 \%)$ de ciclistas, 9 internações $(3,26 \%)$ foram consequentes de outros tipos de acidentes de transporte, 4 internações $(1,45 \%)$ de vítimas de acidentes de veículos pesados de transporte, 2 internações $(0,72 \%)$ de acidentes envolvendo ocupantes de ônibus e 1 internação (0,36\%) de ocupante de caminhonete.

Gráfico 2 - Internações por tipo de acidente

Internações por tipo de acidente

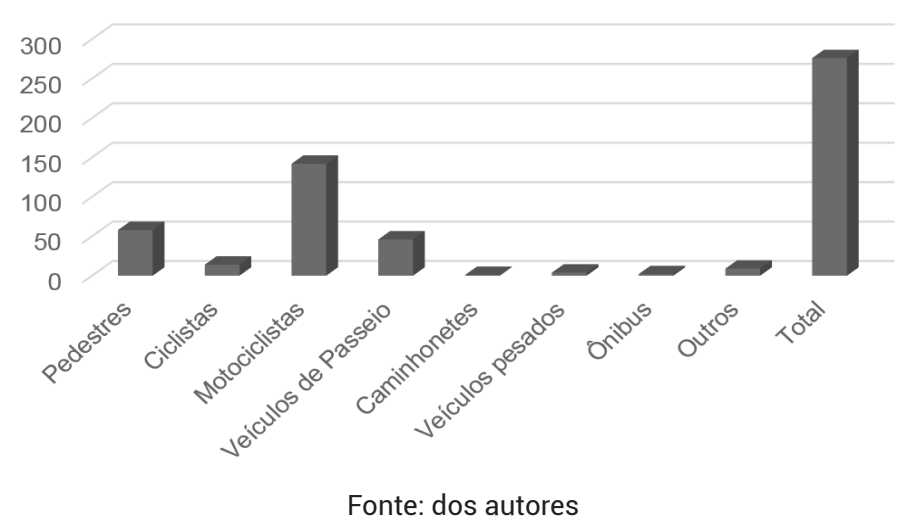

\subsection{Gastos}

O Ministério da Saúde declara ter gastado $\mathrm{R} \$ 420.581,80 \mathrm{com}$ atendimento das vítimas de acidentes automobilísticos (2,16\% do gasto total em saúde). Aproximadamente 46,9\% (R\$197.129,97) dos gastos foram destinados a motociclistas; $22,1 \%(\mathrm{R} \$ 93.018,02)$ a pedestres; $18,4 \%(\mathrm{R} \$ 77.460,84)$ a ocupantes de veículos de passeio; $2,2 \%(\mathrm{R} \$ 9212,92)$ a ciclistas. Os 10,4\% $(\mathrm{R} \$ 43.780,38)$ restantes envolvem gastos com as demais classificações de acidentes de trânsito. 
Gráfico 3 - Gastos com atendimento por tipo de acidente

\section{Gastos com Atendimento}

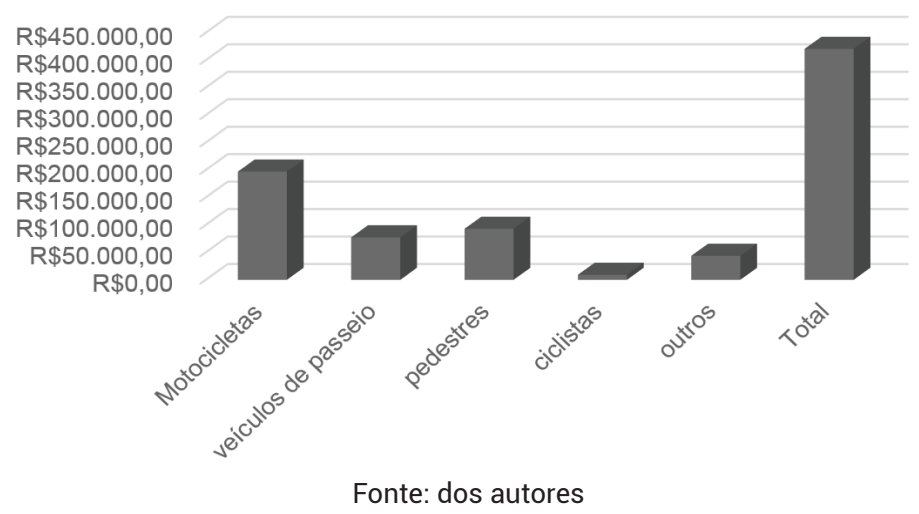

\section{3 Óbitos}

Ocorreram, ao total, 15 óbitos relacionados a acidentes de transporte, sendo 5 (33,3\%) de motociclistas, 5 (33,3\%) de pedestres, 4 (26,7\%) de ocupantes de veículos de passeio, e 1 (6,7\%) classificado como "outros tipos de acidentes de transportes terrestres". Nesse grupo, 12 pessoas (80\%) eram do sexo masculino e $3(20 \%)$ eram do sexo feminino. Quanto à faixa etária, $20 \%$ dos óbitos (3 pessoas) estavam entre 15 e 19 anos; $20 \%$ (3 pessoas) entre 20 e 39 anos; $46,7 \%$ ( 7 pessoas) entre 40 e 59 anos; e 13,3\% (2 pessoas) acima dos 60 anos.

Gráfico 4 - Óbitos por tipo de acidente

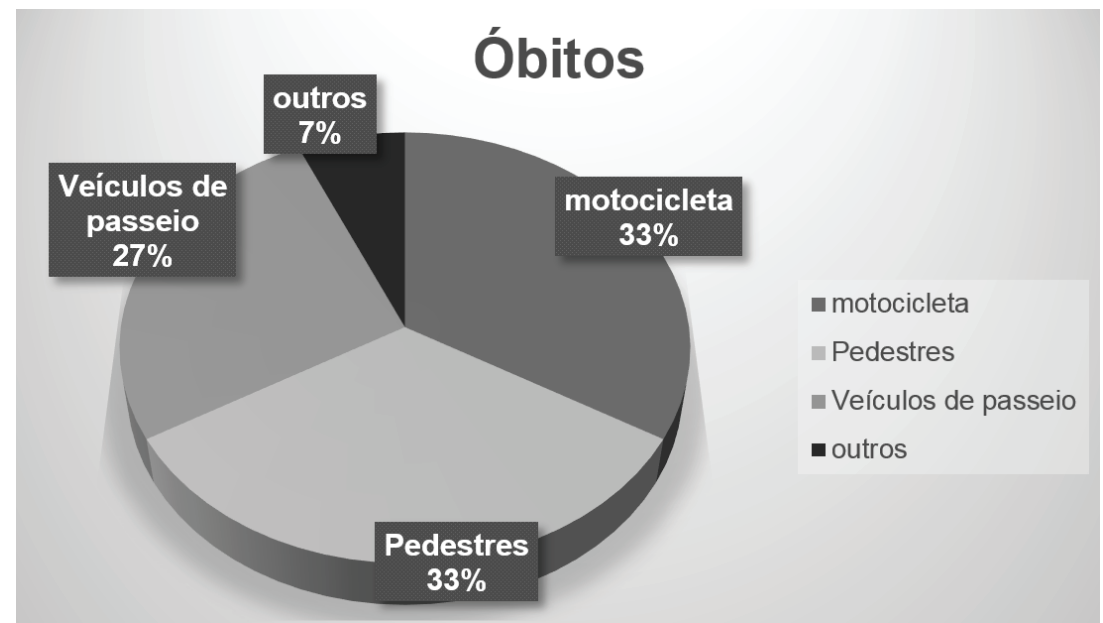

Fonte: dos autores 
Gráfico 5 - Óbitos por gênero

Óbitos por gênero

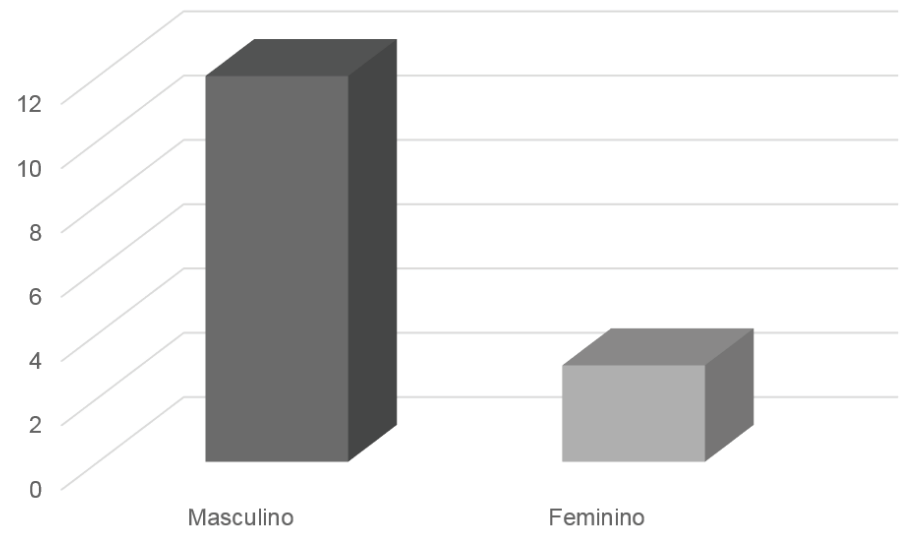

Fonte: dos autores

4.3.1 Óbitos de pedestres

Dos pedestres que evoluíram para óbito, 1 (20\%) tinha entre 30 e 49 anos; 2 (40\%) entre 50 e 59 anos; 1 (20\%) entre 60 e 79 anos e $1(20 \%)$ tinha 80 anos ou mais.

Além disso, 3 (60\%) pessoas eram do sexo masculino e 2 (40\%) do sexo feminino

\subsection{2 Óbitos de motociclistas}

Em relação aos motociclistas, 2 (40\%) tinham entre 15 e 19 anos; 1 (20\%) entre 20 e 29 anos e 2 (40\%) entre 50 e 59 anos.

Todos os óbitos ocorreram em vítimas do sexo masculino (100\%).

\subsection{3 Óbitos de acidentes com veículos de passeio}

Dentro da categoria dos veículos de passeio, 1 pessoa (25\%) tinha entre 15 e 19 anos; 1 (25\%) entre 20 e 29 anos; 1 (25\%) entre 40 e 49 anos e 1 (25\%) entre 50 e 59 anos.

Nesse caso, 3 (75\%) pessoas eram do sexo masculino e 1 (25\%) do sexo feminino

\subsection{4 Óbitos classificados em "outros tipos de acidente de transporte"}

Por fim, o único óbito classificado como "outros tipos de acidentes de transportes terrestres" tinha entre 40 e 49 anos. Esse óbito foi de vítima do sexo masculino.

\section{DISCUSSÃO}

No total, foram registradas 276 internações por acidentes de transporte, no ano de 2015. Considerando que Volta Redonda é uma cidade de pequeno/médio porte, com população estimada em 262.970 habitantes pelo IBGE nesse ano, esse número torna-se bastante expressivo, visto que, para se justificar a internação, o paciente provavelmente é vítima de algum trauma moderado ou grave. Assim, 
se dividirmos essas internações em um período de um ano (apenas para fins didáticos), observamos que durante pouco mais de nove meses (ou seja, mais de $3 / 4$ do ano), houve um paciente vítima de trauma moderado/grave por dia. Porém, é um fator limitante da pesquisa, o fato de não ser possível mensurar a gravidade e os tipos de lesões de cada paciente e o tratamento que cada um necessitou.

Outra observação importante é que a grande maioria dos pacientes internados após acidentes automobilísticos era do sexo masculino $(80,41 \%)$. Além disso, a maioria dos óbitos também ocorreu no sexo masculino (80\%). Esses dados estão em concordância com a literatura levantada para realização desta pesquisa.

Nota-se também que a maioria absoluta das internações ocorreu na faixa-etária da população chamada economicamente ativa, causando grande prejuízo, não só para os serviços de saúde (que atendem o paciente no momento da urgência e promovem um trabalho de recuperação/reabilitação posterior), mas também para as empresas e para a Previdência Social, diante dos afastamentos temporários/definitivos dos funcionários e das faltas decorrentes do trauma sofrido.

Quanto ao tipo de acidente que resultou em internações hospitalares, nota-se que a grande maioria das internações foram de motociclistas $(51,45 \%)$, depois de pedestres $(21,01 \%)$ e de ocupantes de veículos de passeio (16,67\%), tendo menor expressão os outros tipos de acidentes de transporte. As estatísticas de internações envolvendo motociclistas, neste trabalho, foram semelhantes às estatísticas de atendimentos a motociclistas no estado do Paraná, no trabalho realizado por GOLIAS e CAETANO (2013). No nosso trabalho, $51,45 \%$ das internações foram atribuídas a motociclistas, enquanto no artigo citado $54,2 \%$ dos atendimentos foram dedicados a motociclistas. Embora a variável não seja exatamente a mesma nos dois trabalhos (internações $x$ atendimentos), pode-se inferir que a proporção de atendimentos e internações seja semelhante.

Já em relação aos óbitos, houve uma distribuição equilibrada entre motociclistas (33,3\%), pedestres atropelados (33,3\%) e ocupantes de veículos de passeio $(26,7 \%)$, sendo a única discrepância observada nos óbitos em decorrência de "outros tipos de acidentes de transporte" (6,7\%). Observamos também que a maior parte desses óbitos ocorreu em pessoas consideradas economicamente ativas e em idade fértil. Entretanto, outro fator limitante desta pesquisa está relacionado à impossibilidade de definir a proporção de óbitos que ocorreram nos períodos pré e intra-hospitalar (precoce e tardio), dados importantes para criar planejamentos de prevenção de acidentes e otimização dos atendimentos.

Assim, os acidentes automobilísticos se mostraram causa importante de morbimortalidade em Volta Redonda-RJ, como observado no cenário mundial contemporâneo, causando grande impacto na sociedade, visto que são responsáveis por um enorme número de internações, óbitos, gastos e incapacitações (temporários ou definitivas). Dessa forma, fica claro que medidas de prevenção, educação e segurança no trânsito devem ser realizadas, a fim de se reduzir a quantidade e a gravidade desses acidentes, devendo ser direcionadas principalmente aos motociclistas, aos pedestres (e aos condutores no geral, para que respeitem os direitos daqueles) e aos condutores de veículos de passeio. Além disso, é necessária atenção especial aos condutores do sexo masculino e aos motociclistas. Também é necessário traçar estratégias para que os atendimentos pré e intra hospitalares sejam realizados com maior agilidade e qualidade, e criar programas e capacitar equipes de reabilitação das vítimas.

Por fim, é importante também que haja uma fiscalização maior e mais efetiva por parte das autoridades de trânsito, leis rígidas que visem punir os condutores infratores e políticas de educação no trânsito, a fim de reduzir a quantidade e a gravidade dos acidentes. 


\section{REFERÊNCIAS}

ABREU, Ângela Maria Mendes; LIMA, Jose Mauro Braz de; GRIEP, Rosane Harter. Acidentes de trânsito e a frequência dos exames de alcoolemia com vítimas fatais na cidade do Rio de Janeiro. Esc. Anna Nery, Rio de Janeiro, v. 13, n. 1, p. 44-50, Mar. 2009. Disponível em: <http://www.scielo.br/scielo. php?script=sci_arttext\&pid=S1414-81452009000100007\&lng=en\&nrm=iso $>$. Acesso em: 21 out. 2015.

ABREU, Angela Maria Mendes; LIMA, José Mauro Braz de; LIMA, José Mauro Braz de. 0 impacto do álcool na mortalidade em acidentes de trânsito: uma questão de saúde pública. Esc. Anna Nery, Rio de Janeiro, v. 10, n. 1, p. 87-94, Apr. 2006. Disponível em: <http://www.scielo.br/scielo.php?script=sci_ arttext\&pid=S141481452006000100011 Ing=en\&nrm=iso >. Acesso em: 21 out. 2015.

ALMEIDA, Lívia Victório de Carvalho; PIGNATTI, Marta Gislene; ESPINOSA, Mariano Martinez. Principais fatores associados à ocorrência de acidentes de trânsito na BR 163, Mato Grosso, Brasil, 2004. Cad. Saúde Pública, Rio de Janeiro, v. 25, n. 2, p. 303-312, Feb. 2009. Disponível em: <http://www.scielosp.org/scielo. php?script=sci_arttext\&pid=S0102-311X2009000200008\&lng=en\&nrm=iso>. Acesso em: 21 out. 2015.

ALMEIDA, Rosa Livia Freitas de et al. Via, homem e veiculo: fatores de risco associados a gravidade dos acidentes de transito. Rev. Saúde Pública, São Paulo, v. 47, n. 4, p. 718-731, Aug. 2013 . Disponível em: <http://www.scielosp.org/scielo.php?script=sci_arttext\&pid=S0034-89102013000600718\&lng=e n\&nrm=iso>. Acesso em: 21 out. 2015.

BRITO, Jon Mark Praga Xavier De. Incapacidade por traumatismo raquimedular secundário a acidentes de trânsito. Coluna/Columna, São Paulo, v. 10, n. 3, p. 175-178, 2011. Disponível em: <http://www.scielo.br/ scielo.php?script=sci_arttext\&pid=S180818512011000300001\&lng=en\&nrm=iso>. Acesso em: 21 out. 2015.

BROSKA JUNIOR, César Augusto; FOLCHINI, Augusto Bernardo De; RUEDIGER, Ricardo Rydygier de. Estudo comparativo entre o trauma em idosos e não idosos atendidos em um Hospital Universitário de Curitiba. Rev. Col. Bras. Cir., Rio de Janeiro, v. 40, n. 4, p. 281-286, Aug. 2013 . Disponível em: <http://www.scielo.br/scielo.php?script=sci_arttext\&pid=S0100-69912013000400005\&lng=en\&nrm= iso>. Acesso em: 21 out. 2015.

DAVANTEL, Pedro Paulo et al. A mulher e o acidente de trânsito: caracterização do evento em Maringá, Paraná. Rev. bras. epidemiol., São Paulo, v. 12, n. 3, p. 355-367, Sept. 2009 . Disponível em: <http://www.scielosp.org/ scielo.php?script=sci_arttext\&pid=S1415-790X2009000300006\&lng=en\&nrm=iso>. Acesso em: 21 out. 2015.

FREITAS, Mariana Gonçalves de et al. Elderly patients attended in emergency health services in Brazil: a study for victims of falls and traffic accidents. Ciênc. saúde coletiva, Rio de Janeiro, v. 20, n. 3, p. 701 712, Mar. 2015. Disponível em: <http://www.scielosp.org/scielo.php?script=sci_arttext\&pid=S1413$81232015000300701 \&$ Ing=en\&nrm=iso>. Acesso em: 21 out. 2015.

GOLIAS, Andrey Rogério Campos; CAETANO, Rosângela. Acidentes entre motocicletas: análise dos casos ocorridos no estado do Paraná entre julho de 2010 e junho de 2011. Ciênc. saúde coletiva, Rio de Janeiro, v. 18, n. 5, p. 1235-1246, May 2013 . Disponível em: <http://www.scielosp.org/scielo. php?script=sci_arttext\&pid=S1413-81232013001100008\&lng=en\&nrm=iso >. Acesso em: 21 out. 2015.

GOMES, Luana dos Passos; MELO, Enirtes Caetano Prates. Distribuição da mortalidade por acidentes de trânsito no município do Rio de Janeiro. Esc. Anna Nery, Rio de Janeiro, v. 11, n. 2, p. 289-295, June 2007. Disponível em: <http://www.scielo.br/scielo.php?script=sci_arttext\&pid=S1414-81452007000200016\&ln $\mathrm{g}=$ en\&nrm=iso>. Acesso em: 21 out. 2015. 
GORIOS, Carlos et al. Transport accidents among children and adolescents at the emergency service of a teaching hospital in the southern zone of the city of São Paulo.Rev. bras. ortop., São Paulo, v. 49, n. 4, p. 391-395, Aug. 2014. Disponível em: <http://www.scielo.br/scielo.php?script=sci_arttext\&pid=S010236162014000400391\&lng=en\&nrm=iso >. Acesso em: 21 out. 2015.

KLEIN, Carlos Henrique. Mortes no trânsito do Rio de Janeiro, Brasil. Cad. Saúde Pública, Rio de Janeiro, v. 10, supl. 1, p. S168-S176, Jan. 1994. Disponível em: <http://www.scielosp.org/scielo. php?script=sci_arttext\&pid=S0102-311X1994000500012\&lng=en\&nrm=iso>. Acesso em: 21 out. 2015.

MARIN-LEON, Leticia et al. Tendência dos acidentes de trânsito em Campinas, São Paulo, Brasil: importância crescente dos motociclistas. Cad. Saúde Pública, Rio de Janeiro, v. 28, n. 1, p. 39-51, Jan. 2012. Disponível em: <http://www.scielosp.org/scielo.php?script=sci_arttext\&pid=S0102-311X2012 000100005\&lng=en\&nrm=iso>. Acesso em: 21 out. 2015.

OLIVEIRA, Ana Paula Pereira de et al. Possível impacto da "Lei Seca" nos atendimentos a vítimas de acidentes de trânsito em uma unidade de emergência. Esc. Anna Nery, Rio de Janeiro, v. 17, n. 1, p. 54-59, Mar. 2013. Disponível em: <http://www.scielo.br/scielo.php?script=sci_arttext\&pid=S141481452013000100008\&lng=en\&nrm=iso>. Acesso em: 21 out. 2015.

QUEIROZ, Marcos S.; OLIVEIRA, Patricia C. P.. Acidentes de trânsito: uma análise a partir da perspectiva das vítimas em Campinas. Psicol. Soc.,http://www.portuguesxconcursos.com.br/p/significado-palavras-valorconectivos.html Porto Alegre, v. 15, n. 2, p. 101-123, Dec. 2003. Disponível em: <http://www.scielo.br/ scielo.php?script=sci_arttext\&pid=S0102-71822003000200008\&lng=en\&nrm=iso >. Acesso em: 21 out. 2015.

SALDANHA, Raquel Forgiarini et al. Differences between attendance in emergency care of male and female victims of traffic accidents in Porto alegre, Rio Grande do Sul state, Brazil. Ciênc. saúde coletiva, Rio de Janeiro, v. 19, n. 9, p. 3925-3930, Sept. 2014. Disponível em: <http://www.scielosp.org/scielo. php?script=sci_arttext\&pid=S1413-81232014000903925\&lng=en\&nrm=iso >. Acesso em: 21 out. 2015.

SALLUM, Ana Maria Calil; KOIZUMI, Maria Sumie. Natureza e gravidade das lesões em vítimas de acidente de trânsito de veículo a motor. Rev. esc. enferm. USP, São Paulo, v. 33, n. 2, p. 157-164, June 1999. Disponível em: <http://www.scielo.br/scielo.php?script=sci_arttext\&pid=S0080-62341999000200007\&ln $\mathrm{g}=$ en\&nrm=iso>. Acesso em: 21 out. 2015.

SANT'ANNA, Flávia Lopes et al. Acidentes com motociclistas: comparação entre os anos 1998 e 2010. Londrina, PR, Brasil. Rev. Saúde Pública, São Paulo, v. 47, n. 3, p. 607-615, June 2013. Disponível em: $<$ http://www.scielo.br/scielo.php?script=sci_arttext\&pid=S0034-89102013000300607\&lng=en\&nrm= iso>. Acesso em: 21 out. 2015.

SOUZA, Vanessa dos Reis de et al. Análise espacial dos acidentes de trânsito com vítimas fatais: comparação entre o local de residência e de ocorrência do acidente no Rio de Janeiro. Rev. bras. estud. popul., São Paulo, v. 25, n. 2, p. 353-364, Dec. 2008 . Disponível em: <http://www.scielo.br/scielo. php?script=sci_arttext\&pid=S0102-30982008000200010\&lng=en\&nrm=iso>. Acesso em: 21 out. 2015.

ZABEU, José Luís Amim et al. Profile of motorcycle victims from the emergency service of a university hospital. Rev. bras. ortop., São Paulo, v. 48, n. 3, p. 242-245, June 2013. Disponível em: <http://www. scielo.br/scielo.php?script=sci_arttext\&pid=S0102-36162013000300242\&lng=en\&nrm=iso>. Acesso em: 21 out. 2015. 